\title{
Malpractice and avascular necrosis: Legal outcomes
}

\author{
Rose M Carter BA LLB(Hons)
}

\begin{abstract}
RM Carter. Malpractice and avascular necrosis: Legal outcomes. Can J Gastroenterol 1999;13(1):79-84. Every physician, but particularly specialists, have reason to be concerned about medical legal issues. Avascular necrosis has been established as a possible serious complication of steroid treatment in inflammatory bowel disease. Two specific Canadian cases illustrating the sequence of medical history, time, expert testimony and legal outcomes are presented. Awards plus costs in the order of $\$ 1$ million or more were the result of these legal proceedings. The courts stated the major factors in finding liability against doctors were the failure to show the patient had been fully informed of treatment options. There was considerable weight given to expert testimony and the patient recollection of events to support their contentions. Adequate contemporaneous record keeping was absent to contradict evidence of the patients. The judges in both illustrative examples leaned heavily on Supreme Court of Canada guidelines whereby the patient must be informed at all stages of the medical process.
\end{abstract}

Key Words: Inflammatory bowel disease, Malpractice, Risk disclosure, Steroid side effects, Vascular necrosis

\section{Faute professionnelle et nécrose avasculaire : enjeux juridiques}

RÉSUMÉ : Tous les médecins, et particulièrement les spécialistes, ont tout lieu de s'inquiéter des questions de responsabilité médicale. La nécrose avasculaire a été établie comme une complication grave potentielle du traitement stéroïdien dans la maladie inflammatoire de l'intestin. On présente ici deux cas de poursuite intentées au Canada; ces deux cas précis illustrent on ne peut mieux les étapes du processus et les enjeux juridiques, depuis l'histoire médicale, jusqu'au témoignage des experts. Ces poursuites judiciaires se sont soldées par des dommages et intérêts et des frais de cour de l'ordre de plus d'un million de dollars. Les cours de justice ont statué sur les principaux éléments de responsabilité des médecins, soit le défaut de bien informer le patient quant aux options thérapeutiques qui lui étaient offertes. On a accordé énormément de poids au témoignage de l'expert et à la façon dont les patients ont relaté les événements pour appuyer leur requête. Faute de pouvoir fournir des dossiers contemporains pour contredire les preuves fournies par les patients, les juges, dans ces deux cas éloquents, se sont principalement fiés aux directives de la Cour Suprême du Canada en vertu desquelles le patient doit être bien informé, à toutes les étapes du processus médical.
G astroenterologists are at increasing risk of being sued for failing to warn inflammatory bowel disease (IBD) patients of the risk of devastating bone deterioration associated with steroid medications. Because IBD has an increasing incidence and prevalence in the population, attempts are made to treat it through an increasing array of medications. Of specific concern is the use of steroids, which pose a serious risk of causing avascular necrosis (AVN). From a medical malpractice point of view, the doctor may be questioned about whether the patient was told about the specific treatment being suggested, available options and potential consequences of each option, and whether this relaying of information is documented. Many lawsuits involve an array of experts, on both sides, along with serious cost and time consumption for all concerned. In addition, being sued may have a deleterious effect on the doctor's professional career.

In the scientific community the causative relationship between corticosteroid use and AVN remains controversial. If corticosteroids are used, the dosage must be appropriate, and this dosage should be supported by documenting illness severity and consideration of alternatives. The purpose of this paper is to make gastroenterologists aware of the importance of providing patients with enough information for them to make choices in the treatment of their IBD, including the use of steroids, which involves the risk of AVN.

The two cases reported below are major examples of the legal and cost impact of AVN development through steroid use to treat IBD.

Bennett Jones; Department of Oral Health Sciences, Faculty of Medicine and Oral Health Sciences, University of Alberta, Edmonton, Alberta Correspondence and reprints: Ms Rose M Carter, Partner, Bennett Jones, 1000 Canadian Utilities Centre, 10035-105th Street, Edmonton, 


\section{CASE 1}

From July 1975 until May 1976 the plaintiff (the patient) suffered from serious IBD and was treated by a gastroenterologist (1). Part of the treatment consisted of high doses of different forms of corticosteroids.

The patient sued the gastroenterologist, alleging the following:

- that the gastroenterologist breached the standard of care expected of a reasonable competent gastroenterologist of similar skill and experience when prescribing high doses of steroids for a prolonged period of time, causing the patient's AVN;

- that the gastroenterologist failed to disclose the material risks of steroid therapy and to recommend the alternative of surgery until after it should have been considered and undertaken. As such, the patient alleges his consent to treatment was not an informed consent and timely surgery was denied.

The gastroenterologist defended his actions by stating the following:

- that he adequately advised the patient of steroid therapy risks and surgical alternatives; in addition, he recommended surgery to the patient on January 25 , 1976 and a number of occasions thereafter but the patient refused until April 30, 1976;

- that there is no causal relationship between steroid use and AVN when the underlying condition is IBD;

- that where a causal link can be shown between steroid treatment and AVN, the link is dose-related but cannot be shown to be duration-related. In other words, the patient cannot establish that the AVN developed as a probable consequence of the prescribed steroids given after, as opposed to during, the first four to six weeks of acceptable therapy.

\section{BACKGROUND TO ILLNESS}

The patient developed IBD in mid-1974 at age 23. Early colitis was diagnosed by his general practitioner in September 1974. The patient experienced three flare-ups, each worse than the previous, and was referred to the gastroenterologist in July 1975. The gastroenterologist made a tentative diagnosis of proctitis with features of Crohn's disease and treated the patient with sulfasalazine and hydrocortisone suppositories. The patient initially responded, but in October 1975 he had another episode. Increased medication did not work. On December 20, 1975, the patient was started on prednisone $40 \mathrm{mg} /$ day but his condition did not improve.

On January 1, 1976, the gastroenterologist discontinued prednisone and started $80 \mathrm{U} /$ day intravenous adrenocorticotrophic hormone; some improvement in the patient's conditioned followed. Prednisone $40 \mathrm{mg} /$ day was commenced on January 14, 1976, and continued until February 13, 1976, except from January 21 to 25, 1976, when prednisone
$60 \mathrm{mg} /$ day was given. On February 13, 1976, the patient was readmitted to hospital, and the gastroenterologist ordered an increase of prednisone to $60 \mathrm{mg} /$ day. The patient continued this increased dosage until April 21, 1976. The dosage was further increased to $80 \mathrm{mg} /$ day for two days in March and 12 days in late April and early May 1976. The patient was also on peripheral, followed by central, intravenous hyperalimentation.

The gastroenterologist believed that the patient had Crohn's disease until April 30, 1976, when the patient underwent a total proctocolectomy and ileostomy, and was diagnosed with ulcerative colitis. The judge found the doctor committed an error of judgement rather than being negligent when he diagnosed Crohn's disease instead of ulcerative colitis. From May 2, 1976, the gastroenterologist gradually reduced prednisone until the drug was discontinued two months later.

In July 1977 the patient began to experience pain in his right hip. In September 1977 an orthopedic surgeon and rheumatologist diagnosed AVN of the right femoral head, but because of various complications including infection, right hip replacement was postponed until May 1987 (ie, 10 years later). In early 1979, the patient was diagnosed with AVN of the left femoral head, and left hip replacement was done in June 1979.

\section{EXPERT TESTIMONY}

Gastroenterologists called by the patient testified that in 1975 and 1976, AVN was recognized as a rare but potential side effect of corticosteroid use. AVN has been recognized as a complication of steroid therapy since 1960 . The judge was impressed that two orthopedic surgeons who diagnosed AVN automatically associated its development with prolonged use of steroids 18 months earlier. One orthopedic surgeon testified that AVN was recognized as a complication of steroid use since the late 1950s. The defendant gastroenterologist acknowledged that in 1975 and 1976 he was aware that $\mathrm{AVN}$ was a rare but recognized side effect of steroid use. He had never seen or heard of AVN arising from steroid use in IBD treatment.

The clinical pharmacology expert for the gastroenterologist opined that there is no proven association between the development of AVN and the use of high doses of steroids to treat IBD, but that the standard course of steroid treatment should not exceed six weeks. A rheumatologist stated that treatment of IBD with high doses of steroids is to be limited to four to six weeks because of potential complications.

\section{COURT FINDINGS}

Based on expert evidence the judge found the following:

- that AVN was a recognized serious potential complication of steroid use;

- that standard practice in gastroenterology in 1975 and 
1976 was to treat IBD with high doses of steroids for no longer than six weeks before resorting to surgery or reducing maintenance steroid usage;

- that in the mid-1970s the standard treatment for IBD was 40 to $60 \mathrm{mg} /$ day of oral or intravenous steroids for two to three weeks to attempt remission. Steroids can be used for three to four weeks followed by another three to four weeks during which the dosage is tapered. If there is no improvement in four weeks, other therapy should be employed. Use of steroids could continue in gradually reduced dosages for two to three further weeks while employing other conservative modes. Without a favourable result the only option is surgery;

- that surgery was the recommended treatment unless the diagnosis was Crohn's disease, where many doses of steroids was justified because of uncertainty that surgery would be curative;

- that the defendant gastroenterologist breached the standard of care of a reasonable, competent gastroenterologist of similar skill and experience when he continued to administer high doses of steroids after more than six weeks of therapy failed to induce a remission of IBD.

\section{INFORMED CONSENT}

The doctors called for the patient testified two key points.

- Various risks of steroid use should be told to the patient, but because AVN was then, and still is, considered to be a rare complication of steroid use in treatment of IBD, AVN might not be listed and explained as a specific risk. However, when surgery was recommended or had to be undertaken and the patient was reluctant or unwilling to undergo surgery, the risk of AVN from continued use of high dosage steroids must be explained. A prudent gastroenterologist would have recommended surgery no later than six weeks after unsuccessful treatment with steroids. In this case, surgery should have been strongly urged to the patient on February 13, 1976.

- Another expert stated that he would warn a patient of all side effects of steroids; however, it was not his practice to describe AVN as a risk, even though in 1975 and 1976 it was a complication of steroid use.

The defendant gastroenterologist testified that it was not his practice in 1975 and 1976 to warn patients about the risk of developing AVN as a result of steroid therapy.

\section{CANADIAN LAW}

A patient must be sufficiently informed of all material risks associated with any form of treatment in order to make an informed decision. A risk that is a mere possibility is not a material risk unless its consequences, even though rare in occurrence, are serious (2). The question arising from evidence in this case is whether AVN arising from high dosage steroid use in IBD treatment was recognized in 1975 and 1976 as a risk that fell within the scope of the rule found in Canadian law. In the 1974 edition of the Compendium of Pharmaceuticals and Specialties (3) (CPS), AVN of femoral and humoral heads is noted as an adverse effect of prednisone.

Based on expert evidence the judge found that because of serious side effects associated with steroid use, duration of treatment with high doses of steroids was limited in 1975 and 1976 to six weeks. Therefore, a reasonably competent gastroenterologist practising at that time would have warned patients who were taking high doses of steroids for IBD treatment of the risks of developing AVN before carrying on with therapy beyond the recognized six weeks.

\section{RECORD KEEPING}

The defendant gastroenterologist said surgery was initially discussed with the patient on January 25, 1976, because of his lack of improvement. The patient testified he asked for surgery and the defendant gastroenterologist said it was too soon to consider surgery. The doctor's notes did not mention such discussions. The judge found it significant that there was no mention that surgery was necessary on the discharge summary dated January 26, 1976. Neither was there any mention in the history notes recorded the day before the discharge summary was dictated. Furthermore, the patient said that when he was very ill and readmitted to hospital on February 13, 1976, and steroid medication was increased from 40 to $60 \mathrm{mg} /$ day, he asked about surgery. The defendant gastroenterologist again said that it was too early to consider surgery.

Given that there are no contemporaneous records to support the evidence of the defendant gastroenterologist regarding discussions of surgery, the judge preferred the patient's evidence.

\section{THE EXPERTS}

The experts testified that if a patient refuses surgery, a prudent gastroenterologist makes a note in his or her record, stating that the option was discussed and refused. The prudent gastroenterologist would enlist support of the patient's family (and perhaps close friends) and other doctors to assist in changing the patient's mind. The defendant gastroenterologist took none of these steps. Despite the gastroenterologist's evidence, the judge held that the gastroenterologist had probably not recommended surgery to the patient before late April 1976 and possibly did not recommend it until just before it was performed.

The judge found that a reasonable person, properly informed of risks associated with prolonged use of high doses of steroids, would consent to surgery after six weeks of unsuccessful steroid therapy. Another question, in law, then became whether this patient would have done so if the risks had been properly explained on readmission to hospital on February 13, 1976. The judge held that because the patient did not refuse major surgery when recommended, the patient would have undergone surgery February 13, 1976. 


\section{CAUSATION}

The judge then considered the issue of causation. The onus in law rests with the patient to demonstrate, on a balance of the probabilities, that high doses of steroids administered by the defendant gastroenterologist beyond the duration of treatment that was in 1975 sanctioned as a reasonable standard of care, caused or contributed in a material way to the patient's development of AVN in both hips. The judge held that the evidence established that AVN probably resulted from steroid treatment administered in 1975 and 1976. It is both reasonable and in accordance with the common sense approach to conclude that steroids administered in the first six weeks of treatment and the 11 weeks thereafter probably contributed cumulatively to development of AVN. Based on evidence of the gastroenterologists, including the defendant, and orthopedic surgeons acting as experts, the judge found that steroid use was the cause of AVN.

\section{AWARD}

The patient was awarded general damages, loss of income to date of trial, loss of future earning capacity, cost of future care, management allowance, interest and costs. The cost of defending the action brought the total cost of this action to approximately $\$ 1$ million. It was 14 years from diagnosis to decision. The gastroenterologist went to the Court of Appeal, but his appeal was dismissed.

\section{CASE 2}

The patient sued his treating internist, claiming he was negligent in diagnosis and care given (4). At age 22, the patient developed $\mathrm{AVN}$ of both femoral heads and will require right and left hip replacements.

The following issues were brought before the judge.

- Did the patient suffer from Crohn's disease?

- If he did not suffer from Crohn's disease, was the internist negligent in diagnosing Crohn's disease?

- Does prednisone cause AVN of the femoral heads?

- Was the internist negligent in prescribing prednisone in this case?

- Was the internist negligent in failing to inform the patient of the risks of prednisone?

Before June 1979 the patient's health was described as excellent. On June 18, 1979, the patient ate chicken that had been taken out of a freezer on June 14, 1979. Shortly after consuming the chicken, the patient became nauseous and experienced stomach cramps, vomiting and diarrhea, and he thought that he had blood in the diarrhea. On June 20, 1979, he visited his family doctor, who gave him a prescription. The vomiting, diarrhea and stomach cramps became worse. On June 21, 1979, the patient called his doctor who arranged for him to see the defendant internist.

When dealing with the patient, the internist was not told about consumption of the chicken. Various examinations were done, including a sigmoidoscopy which showed blood in the rectal area coming from an area above it. The lining of the lower area of the rectum was normal. The internist concluded that Crohn's disease was the most likely possibility, but an infective process would have to be ruled out. An x-ray of the colon taken on June 22, 1979, was normal. Stool tests were negative for infection but confirmed blood. The patient had an elevated white blood cell count. The patient testified that by June 24, 1979, he "felt great".
On June 26, 1979, the radiologist reported that the barium meal and follow-through indicated that transit of barium through the small intestine was excessively rapid, and concluded it was possible the patient had "very early signs" of Crohn's disease. Before this report, the internist had intended to discharge the patient. Instead, he cancelled the discharge order and started treating the patient for Crohn's disease with oral prednisone $60 \mathrm{mg} /$ day to be tapered gradually over three months.

The patient has had no recurrence of symptoms. Given the evidence of medical experts that Crohn's disease tends to recur, the judge found it probable the patient was not suffering from Crohn's disease in 1979. The defendant internist saw the patient on July 16 and August 7, 1979, and he was asymptomatic. However, given that Crohn's disease is difficult to diagnose, the judge concluded, based on expert evidence, that the internist made an error of judgement and was not negligent in diagnosing Crohn's disease in June 1979.

The patient's hips began to trouble him in October 1979. By February 1980, the patient was unable to work and was referred to an orthopedic surgeon. He had considerable pain in both hips and demonstrated massive AVN of femoral heads. He remained off work until March 1982, left work in October 1982 because of pain in both hips, and returned to work in April 1983 and was still employed at the time of trial. His marriage broke down, and his wife left him in October 1982. She testified that he was angry and bitter. The judge found that there was little doubt that the marriage breakdown was due, to a considerable extent, to the patient's physical and mental state.

The patient underwent the following operations.

- March 31, 1980 - An osteotomy of the left hip with bone grafting from the iliac crest.

- April 5, 1980 - Further surgery because of postoperative infection.

- January 7, 1981 - An osteotomy of the right hip with bone grafting. 


\section{THE EXPERTS}

A clinical pharmacologist, a number of doctors (including the patient's treating orthopedic surgeon) and two gastroenterologists gave evidence at the trial. The CPS, which in its 1979 edition listed adverse effects for prednisone including "aseptic necrosis of femoral and humeral heads", was relied upon for indicating the level of drug knowledge at that time (5).

The pharmacologist testifying on behalf of the patient opined that AVN of the femoral heads was, in all probability, caused by the prednisone prescribed by the internist. The orthopedic surgeon concurred. The gastroenterologist testifying on behalf of the internist said that he could not recall a case where treatment of Crohn's disease with prednisone led to necrosis of the femoral head. In his experience he had never seen a short course of prednisone lead to necrosis of the hips.

The judge accepted the evidence of the pharmacologist called on behalf of the patient rather than the evidence of the gastroenterologist called on behalf of the internist. The judge concluded that AVN was due to the rare - but known - complication of prednisone intake.

\section{WAS THE INTERNIST NEGLIGENT IN PRESCRIBING PREDNISONE?}

The pharmacologist testified that the indication for prednisone in the treatment of Crohn's disease is an acute fulminant process that threatens to progress to potential life-threatening complications. There were insufficient symptoms in June 1979 to justify further therapy.

The gastroenterologist who attended the patient in 1980 and testified on behalf of him stated the following:

- that the patient had recovered from all manifestations of Crohn's disease by June 26, 1979;

- that it was inappropriate to prescribe prednisone on June 26, 1979, because the patient was asymptomatic, no longer suffered from diarrhea or abdominal pains and was feeling almost recovered;

- that prednisone does not have a curative effect on Crohn's disease but treats symptoms. There is no benefit from continuing with long term treatment with prednisone once symptoms have resolved. (A gastroenterologist testifying for the defendant stated that prednisone is not prescribed to control symptoms); and

- that, rarely, prednisone may give rise to aseptic necrosis of the hip and other joints.

Another gastroenterologist called for the defence thought it was reasonable to prescribe prednisone on June 27,1979 , but tempered this by saying prescribing would depend on disease activity. He agreed that the patient did not have symptoms on June 27, 1979, and if the symptoms continued to improve there was no need for prednisone.

The judge found that the treatment by the internist fell below the standard of care and skill reasonably expected of a specialist in gastroenterology when the internist prescribed prednisone. The judge found that the complication of AVN of femoral heads with a short dose of prednisone is known but unusual. While the particular side effects suffered by the patient were not reasonably foreseeable, it was foreseeable that damage might occur to the patient's health and, as such, the internist was liable.

\section{CONSENT}

The patient testified that the internist did not inform him of any potential side effects of prednisone. The internist testified that he always tells patients of side effects, and specifically told this patient of certain side effects including swelling, weight gain, possible facial fullness and stomach pains, and that there might be a change in his blood sugar levels. The judge preferred the evidence of the patient.

\section{THE LAW}

Under Canadian law, a patient must be sufficiently informed to enable him or her to make a choice about whether to submit to therapy. Any material risks should be disclosed. A risk that is a mere possibility ordinarily does not have to be disclosed, but if its occurrence may result in serious consequences, such as paralysis or death, then it should be treated as a material risk and be disclosed (2).

The law states that if the patient was told of the risks of prednisone and then had decided to take the drug, or if a reasonable person in the patient's position would have taken the drug after being informed of the risks, then negligence in failing to inform this patient adequately of the risks and benefits would not be the cause of his damages.

The patient testified that he would have refused prednisone if he had been told there was one chance in 500 that his hip joints would degenerate. He further stressed that he would not have taken the drug if he had been told there was an adverse effect because he had no symptoms and no need for the drug in June 1979.

Based on the evidence, the judge ruled that had the patient been adequately informed of the risks and benefits of taking prednisone he would not have taken the drug. He held the internist was negligent in failing to advise the patient properly of the risks of taking prednisone, and that the internist's negligence was the cause of the damages.

\section{AWARD}

Treatment for Crohn's disease commenced in June 1979. The trial was heard in May and June 1984, and judgement rendered on July 30, 1984, about five years after treatment commenced. Damages of $\$ 750,000$ plus costs were awarded, and in conjunction with the cost of defending the action, the total cost was about $\$ 1$ million.

\section{DISCUSSION}

The two cases presented here are typical of medical negligence actions in terms of the process, but because of the severity of medical and financial outcomes they are atypical in size of the awards. As a general rule, court awards appear to 
be increasing, which have obvious effects on defendant doctors and the medical community as a whole, including gastroenterologists. With a recent award in Canada of $\$ 15$ million against a pediatrician who failed to diagnose pneumococcal meningitis in a child, it is apparent that the courts are placing a different emphasis on stresses and effects on patients and families, and are awarding monies accordingly (6). Stress on the defendant doctor, and his or her family and associates, is another aspect that must be dealt with because the time from diagnosis and treatment until court outcome can be as much as 15 years, almost half of a professional career. It is now documented and clear that according to evidence accepted by the courts, AVN is a recognized complication of steroid therapy. Although this specific type of problem is unlikely to occur today, there may well be other types of complications in practice that may be controversial, but within a short time would be standard in the medical community. The courts are consistent in the view that patients should be informed at all times of risks and options. These cases reinforce the importance of communication through diagnosis and treatment.

How do doctors best protect themselves to avoid potential crises? The guidelines are as simple as providing good care; informing the patient (and family where appropriate) of potential treatments, options and side effects of medications; and, above all, keeping complete contemporaneous records and maintaining reasonable open communication with patients.

Judgements in the two cases reviewed revolved around these issues and make it clear that the courts are implementing the rule of law whereby patients are entitled to information to enable them to give an informed consent.

\section{REFERENCES}

1. Levitt v Carr (June 27, 1989), Vancouver Registry No 1236/C843378 (BCJ); affd (1992) 66 BCLR (2d) 58 (BCCA).

2. Reibl v Hughes (1980), 114 DLR (3d) I (SCC).

3. Compendium of Pharmaceuticals and Specialties, 9th edn. Ottawa: Canadian Pharmaceutical Association, 1974.

4. Graham (next friend of) v Persyko (July 30, 1984) OJ No 430 (SC Ont)

5. Compendium of Pharmaceuticals and Specialties, 14th edn. Ottawa: Canadian Pharmaceutical Association, 1979.

6. Daan (Litigation Guardian of) v Chiavaro (30 May 1996), OJ No 1912 (Ont CJGD). 


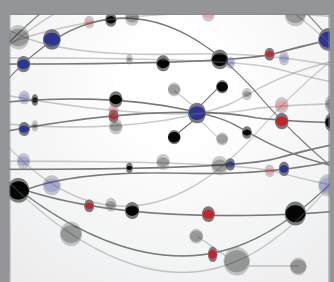

The Scientific World Journal
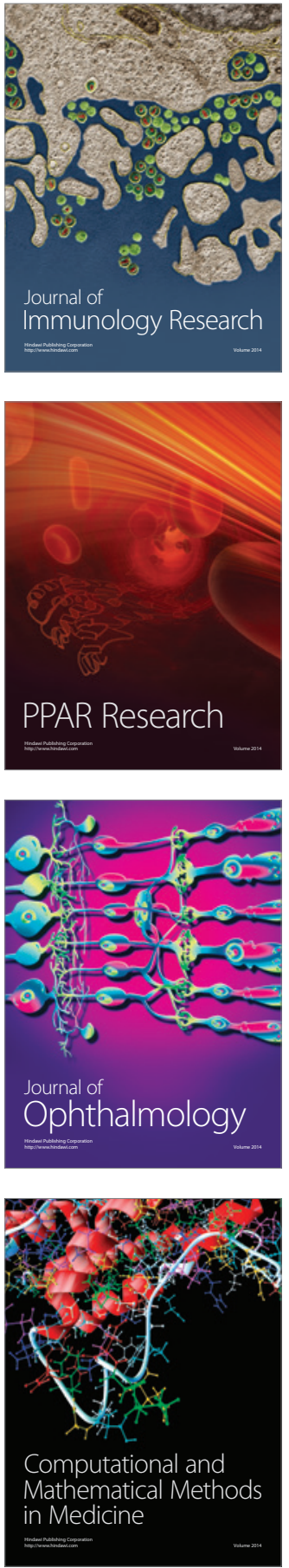

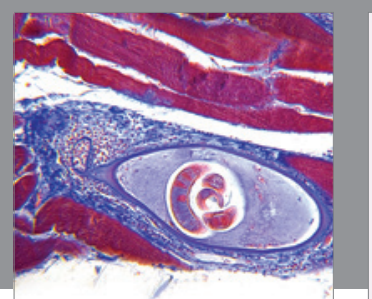

Gastroenterology Research and Practice

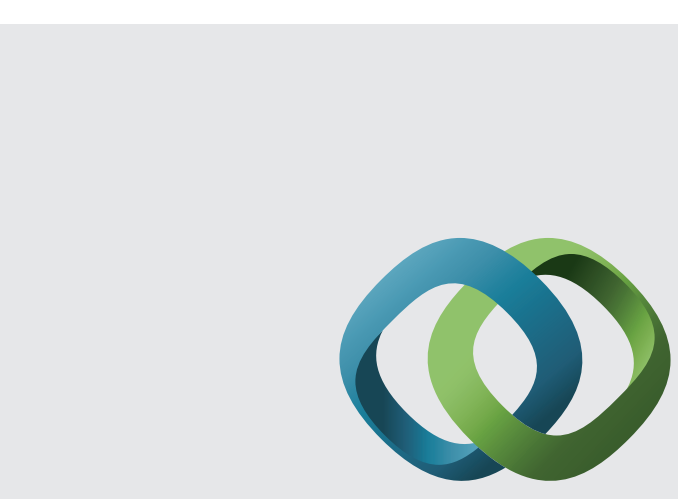

\section{Hindawi}

Submit your manuscripts at

http://www.hindawi.com
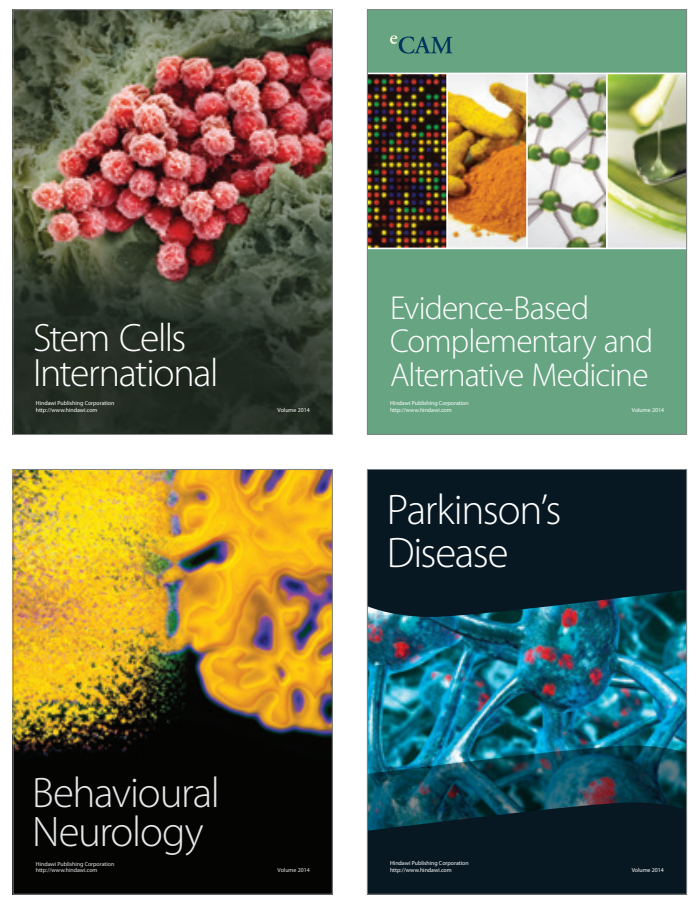
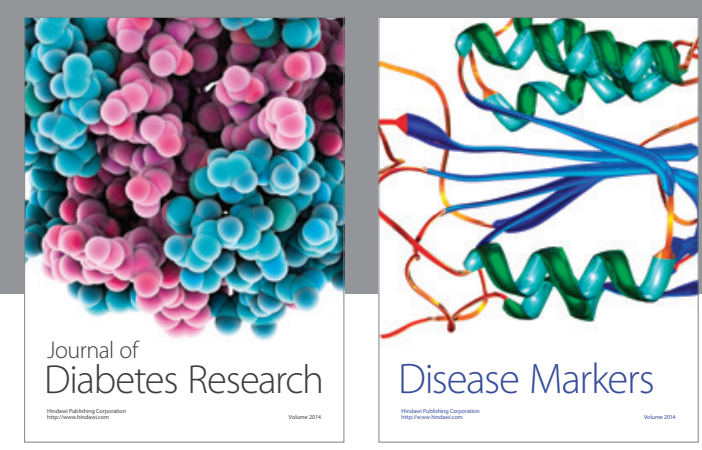

Disease Markers
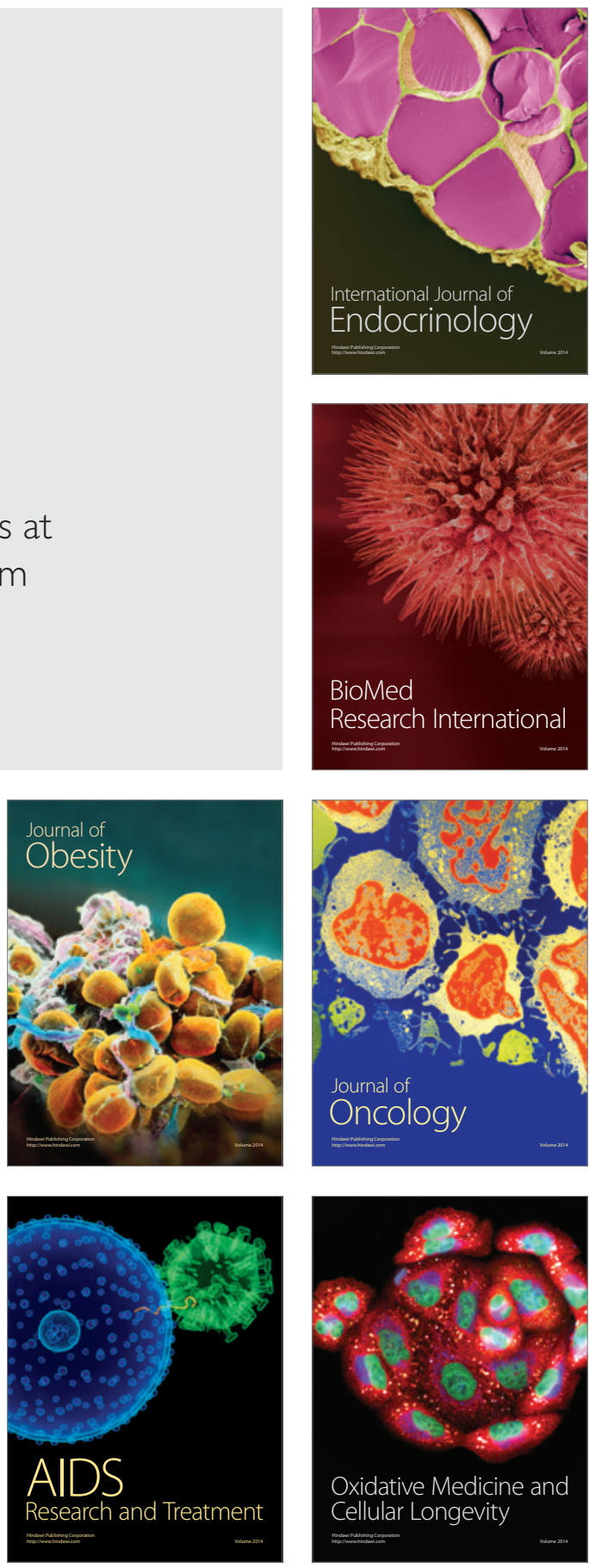